\title{
HISTÓRIA DO DIREITO: ANÁLISE DO ESTATUTO EPISTEMOLÓGICO
}

\author{
Adelcio Machado dos Santos ${ }^{1}$ \\ Dreone Mendes ${ }^{2}$ \\ Rubens Luis Freiberger ${ }^{3}$
}

Recebido em 01/06/2021

Aceito em 09/08/2021

\begin{abstract}
RESUMO
A História do Direito consiste na disciplina responsável pelo estudo das fontes externas do Direito, ou seja, como ele nasce, evolui e se transforma para finalmente chegar ao presente. Atualmente, examinar e problematizar as relações entre História e Direito reveste-se da maior importância, especialmente quando se tem em conta a percepção da normatividade extraída de um determinado contexto histórico definido como experiência pretérita que conscientiza e liberta o presente. $\mathrm{O}$ início da história do direito remonta à época em que os homens passaram a viver em grupos organizados, dando origem à formação de comunidades, sendo que a partir daí sentiram eles a necessidade de disciplinar a sua própria conduta, traçando normas de respeito aos direitos de cada um. O estudo da História do Direito resulta na utilidade jurídica para a compreensão da origem do ordenamento jurídico e sua ligação com os institutos do passado, no qual o direito atual tem sua origem. É praticamente impossível desvincular o estudo do direito de suas origens, pois a compreensão completa de uma legislação exige o conhecimento da história de sua formação.
\end{abstract}

PALAVRAS CHAVE: Direito. História. Formações Jurídicas.

\section{HISTORY OF LAW: ANALYSIS OF THE EPISTEMOLOGICAL STATUS}

\begin{abstract}
History of Law consists in the discipline responsible of the study of the extenal sources of Law, that is, the way it is born, evolutes and transforms until it finally gets to present days. Nowadays, examining and problematizing the relations between History and Law gets coated by a relevant importance, specially when one takes into account the perception of normativity extracted from a certain historical context defined as past experience which gives conciousness to the present and sets it free. The beginning of history of law goes back to the time when men started to live freely in organized groups, giving origin to the formation of communities, being that from that moment on they felt the need to discipline their own way of being, giving rules of respect to each one's rights. The study of History Law results in the juridical utility for the comprehension of the origin of juridical ordination and its link with the institutes of the past, in which the current law has its origin. It is practically impossible to separate the study of law from its origins, for the
\end{abstract}

\footnotetext{
${ }^{1}$ Doutor em Engenharia e Gestão do Conhecimento (UFSC). Pós-Doutor (UFSC). Docente, pesquisador e orientador no Programa de Pós-Graduação em Desenvolvimento e Sociedade da (Uniarp). Advogado (OAB/SC $n^{\circ}$ 4912), Endereço: Rua Prof. Egídio Ferreira, $n^{\circ}$ 271, Apto. 303 - 88090-500 (SC) Brasil. E-mail: adelciomachado@gmail.com.

${ }^{2}$ Mestrando do Programa de Pós-Graduação em Desenvolvimento e Sociedade da Uniarp.

${ }^{3}$ Mestrando do Programa de Pós-Graduação em Desenvolvimento e Sociedade da Uniarp.
} 
complete comprehension of lawmaking demands the knowledge of the history of its formation.

Keywords: Law. History. Juridical formations.

\section{INTRODUÇÃO}

Assim, será igualmente demonstrado as profundas consequências sociais que a corrupção causa nos países em desenvolvimento e sua minoração em relação aos países que aplicam efetivamente o compliance. A história compreende a narração dos fatos jurídicos importantes, possibilitando a retratação do suceder da humanidade através dos tempos, afirmam Pinheiro e Bekhor (1997). É a experiência atual do presente que conduz à busca histórica. O fazer historiográfico sempre parte do presente, as perguntas e inquietudes são levantadas no tempo atual e as respostas são buscadas no passado.

Em outras palavras, o historiador parte de questionamentos do presente, atribuindo importância aos fatos do passado, em busca da comprovação dos mesmos por meio de evidências a serem investigadas em fontes documentais oficiais e não oficiais. As fontes são submetidas a análises críticas para verificar a originalidade do documento.

Destarte, se o historiador se limita a narrar uma história, pura e simplesmente, ainda que por forma artística não será uma ciência. Senão um gênero literário. Entretanto, a partir do momento em que ele desenvolve uma análise científica dos feitos passados, pesquisando as suas causas e suas projeções no futuro, não se poderá deixar de reconhecer que ela assume a posição de uma ciência jurídica (PINHEIRO E BEKHOR, 1997).

A história pode ser entendida como uma ciência não no sentido de uma ciência de laboratório que segue rígidos métodos experimentais, mas como uma investigação crítica acerca dos fatos históricos, que exigem do historiador a perspicácia racional para identificação das verdades históricas. O historiador questiona uma noção de tempo, já que o conjunto dos agentes históricos existe em múltiplos ritmos temporais; indaga-se sobre o sujeito ou sujeitos responsáveis pelo movimento histórico; incorpora-se outras experiências e nelas se testa a pertinência de conceitos e categorias teóricas (MALUF, 1995).

\section{DESENVOLVIMENTO}

Destarte, é possível verificar que a história não se constrói somente com base nos acontecimentos oficialmente registrados, pois há uma série de documentos que não são inocentes, mas constituem vestígios que necessitam ser analisados. A história puramente 
científica exclui muitos fatos, por não estarem dentro do rigor científico. Há um conjunto de agentes históricos variados que seguem diferentes ritmos temporais e divergem quanto à percepção de tempo.

O estudo histórico permitiu construir uma concepção das sociedades humanas como estruturas globais, historicamente específicas, totalidades organizadas complexas, mas cognoscíveis, sujeitas à regularidades e determinações. $\mathrm{O}$ historiador realiza constantes recortes nos acontecimentos passados, visto que é impossível tomar conhecimento de todos os fatos e do modo exato como ocorreram no passado.

Destarte, Cardoso (1981) sustenta que a história é um processo de seleção que se realiza atendendo-se à relevância histórica.

Assim, como o historiador seleciona do oceano infinito dos dados os que têm importância para o seu propósito, assim, também extrai da multiplicidade das seqüências de causa e efeito somente as historicamente significativas. O padrão pelo qual rege a relevância histórica é sua capacidade de fazer com que se encaixem no seu quadro racional de explicação e interpretação.

As demais seqüências de causa e efeito devem ser recusadas como algo acidental, não porque seja distinta a relação de causa e efeito, e sim porque a própria seqüência é irrelevante. O historiador nada pode realizar com ela, pois não é redutível a uma interpretação racional, carece de significado tanto para o passado quanto para o presente (CARDOSO, 1981).

Dessarte, como as mais diferentes instituições sociais, documentos, fontes, vestígios, a evolução do direito também sempre foi objeto de análises históricas. Para Pinheiro e Bekhor (1997), desvincular o estudo do Direito de suas origens parece ser quase impossível. Para se conhecer bem uma legislação, é necessário ter conhecimento de sua história. Há uma sucessão de fatos no evolver da história que se entrelaçam e se completam, dando origem ao sistema contemporâneo do Direito.

Conforme Pinheiro e Bekhor (1997), a História do Direito, como uma área específica dentro da história, é aquela que cuida do estudo das fontes externas do Direito, isto é: como ele nasce, evolui e se transforma para finalmente chegar ao presente.

A História do Direito pode ser dividida em interna e externa. A história interna que ocupa um campo específico do direito, compreende um estudo material das instituições públicas e privadas, enquanto a história externa é formal, extrínseca e responsável por examinar as fontes do Direito, ou seja, a maneira como surgem as normas jurídicas.

A História do Direito se relaciona com todas as disciplinas que dizem respeito às fontes da história geral, como a Psicologia, a Lingüística, a Biologia Humana, a Geografia Social, 
entre outras. Ela também pode ser dividida em História Geral e Especial do Direito. A primeira trata do Direito como um todo, estudando a evolução das idéias e formas jurídicas através dos tempos. Já a segunda cuida do direito, sob um único ângulo ou de um só ramo do direito, como a História das Instituições Políticas, do Direito Penal, do Direito Civil, etc. (PINHEIRO E BEKHOR, 1997).

A História do Direito não é constituída simplesmente de uma mera narração de fatos jurídicos, pois ela não se pode limitar a este aspecto. Esse ramo da história necessita buscar o conhecimento científico das causas geradoras da norma, do ambiente em que foi gerada, do sentido humano que a sustentou através dos tempos.

De acordo com Wolkmer (2003), examinar e problematizar as relações entre História e Direito reveste-se hoje da maior importância, principalmente quando se tem em conta a percepção da normatividade extraída de um determinado contexto histórico, definido como experiência pretérita que conscientiza e liberta o presente.

Obviamente, tal preocupação está dissociada de uma historicidade do jurídico, delineada por toda uma tradição teórico-empírica assentada em proposições revestidas pela força da continuidade, da previsibilidade, do formalismo e da linearidade.

Porém, para alcançar nova leitura histórica do fenômeno jurídico, enquanto expressão de idéias, pensamento e instituições, é necessário apurar a distinção das especificidades inerentes a cada campo científico do que seja História, do que seja Direito, bem como o sentido e a função de uma interpretação que se reveste do viés tradicional ou crítico.

$\mathrm{Na}$ trajetória da cultura jurídica moderna há consenso de que áreas de investigação, como História do Direito, História das Instituições Jurídicas e História das Idéias ou do Pensamento Jurídico, estão todas identificadas, ora com um saber formalista, abstrato e erudito, ora com uma verdade extraída de grandes textos legislativos, interpretações exegéticas de magistrados, formulações herméticas de jusfilósofos e institutos arcaicos e burocratizados (WOLKMER, 2003).

Entretanto, conforme Wolkmer (2003), essa longa tradição foi interrompida nas últimas duas décadas por um renovado interesse de natureza crítico-ideológica por questões metodológicas sobre a História do Direito. Essa mudança de visão reflete também o esgotamento de determinado tipo de historiografia jurídica que tem por base os valores liberalindividualistas.

Essa retomada do viés historicista sobre as idéias ou as instituições jurídicas procura superar a profunda crise que se abateu sobre esse campo de pesquisa. A pouca relevância da disciplina não se deve à falta de especialistas ou aficionados, mas muito mais em função de 
uma crise motivada por sua falta de significado e pela dificuldade de encontrar uma função que realmente justifique sua existência, defende Wolkmer (2003).

Uma análise atenta sobre os motivos do esgotamento da História do Direito realça o fato de que a historiografia jurídica da modernidade, formada em grande parte por princípios e valores liberal-burgueses, desempenha dois objetivos muito claros. $\mathrm{O}$ primeiro deles refere-se à relativização e, conseqüentemente, desvalorização da ordem social e jurídica pré-burguesa, apresentando-a como fundada na irracionalidade, no preconceito e na injustiça. $\mathrm{O}$ segundo objetivo diz respeito à realização da apologia da luta da burguesia contra essa ordem ilegítima e a favor da construção de um Direito e de uma sociedade 'naturais', e harmônicos, ou seja, libertos da arbitrariedade e historicidade anteriores.

A crítica burguesa realizada contra o antigo Direito e as organizações político-feudais gerou efeitos e foi eficaz num primeiro momento histórico, porém acabou perdendo significado com a edificação da ordem e da hegemonia liberal-individualista.

Deste modo, a missão da historiografia tornou-se mecanismo de endeusamento da ordem jurídica, política e social do modo de produção capitalista, na medida em que o espaço institucionalizado passa a ser coberto por um universo ideológico apresentado como uma situação natural e independente do devir histórico. Daí resulta o fato de a historiografia jurídica, dependente dos textos legais e da exegese de seus maiores destaques, orientar-se, ao mesmo tempo, rumo a um formalismo técnico-dogmático ou a uma antiquada erudição da vida social (WOLKMER, 2003).

Desta maneira, alguns juristas-historiadores declinaram para uma narrativa conservadora e dogmática que objetivava a justificação da ordem social e jurídica vigente, tentando provar que ela mergulhava na tradição, no espírito nacional, ou que resultava num lento progresso do 'espírito humano.' Essa postura desenvolvida pelos juristas historiadores negligenciava toda e qualquer explicação do Direito por um processo dinâmico, inserido no contexto de conflitos e tensões sociais.

De acordo com Wolkmer (2003), outra tendência dos operadores do legalismo, no meio acadêmico, era a não consideração de uma historicidade das instituições que possibilitasse, na formação dos juristas, a prática de condutas eficazes e legitimamente identificadas com os problemas da sociedade.

Segundo Hespanha (apud WOLKMER, 2003), com isso, favorecia-se a oficialização de uma historiografia erudita e passadista que tendia a refugiar-se nas épocas historiográficas mais remotas e em discussões meramente teórico-acadêmicas de cunho idealista/abstrato.

O problema crítico do conhecimento histórico é deixado de lado pelo surto do 
historicismo tradicional, ocultando-se no suposto mito da neutralidade do saber e da universalidade dos princípios da ciência positivista, expressão da fase concorrencial do sistema capitalista. Assim, a construção do conhecimento histórico acerca do direito ordena-se por uma perspectiva linear, estática e conservadora.

Essa maneira estática do fazer histórico forja um conhecimento histórico-elitista, fundamentado na construção mútua da neutralidade da cultura e dos intelectuais, transformados numa espécie de instância arbitral colocada acima dos conflitos de classe.

$\mathrm{Na}$ medida em que a historiografia tradicional (liberal-burguesa) passa a ser simples disciplina de justificação da ordem legal imperante e da acumulação de conhecimentos para a chamada "cultura superior", sem fins úteis para com a realidade, a História do Direito perde sua significação e entra em constante descrédito, constituindo-se num campo do saber de pouca utilidade, acabando seus pressupostos por sucumbir numa crise de eficácia.

As profundas transformações epistemológicas nas ciências humanas, os novos interesses, a insurgência de conflitos sociais e as recentes transformações por que vêm passando as formas de vida contemporânea determinam uma renovação metodológica nos estudos históricos das instituições jurídicas e políticas, sustenta Wolkmer (2003).

Destarte, é necessário redefinir, na historicidade da crise, os novos marcos teóricometodológicos que possibilitam alcançar novo paradigma, envolvendo modalidades alternativas de interpretação, pesquisa e investigação histórica. Não mais uma historicidade linear, elitista e acumulativa, porém problematizante e transformadora.

\section{IMPORTÂNCIA DA DISCIPLINA DE HISTÓRIA DO DIREITO}

É praticamente impossível desvincular o estudo do Direito de suas origens, visto que a compreensão completa de uma legislação exige o conhecimento da história de sua formação. $\mathrm{O}$ estudo da História do Direito evidencia o que ele foi no passado e o caminho que percorreu para chegar ao Direito contemporâneo.

Tem-se assim que a importância da disciplina de História do Direito no ensino deve-se a essa dependência que o direito atual possui em relação ao passado, pois o direito de hoje não é algo novo, mas pelo contrário resulta da atuação de forças no passado. O que hoje vigora brotou dos germes existentes no passado. Conforme ressaltam Pinheiro e Bekhor (1997), o direito não se inventa, pois é um produto lento da evolução, adaptado ao meio. Não há a possibilidade de se fazerem leis inteiramente novas. 
As normas vigentes na sociedade contemporânea constituem sempre uma reprodução, com ou sem modificações de preceitos preexistentes. No entanto, é importante ressaltar que ao se falar em reprodução do que já existe, não se está afirmando a impossibilidade de se fazer uma lei inédita.

Essa colocação é efetuada tomando-se o direito positivo atual como um todo, um Código, uma Constituição, etc. e não uma eventual lei disciplinando um assunto isolado, visto que esta poderia ser inteiramente nova, mesmo porque, sabe-se, o direito acompanha a evolução da sociedade e os progressos científicos e tecnológicos. Desta forma, hoje se pode falar em um direito à imagem, direito espacial, por exemplo, ambos desconhecidos na Antigüidade (PINHEIRO E BEKHOR, 1997).

Assim, é de suma importância conhecer o passado, pois o direito vigente na atualidade constitui um desdobramento do passado. Só é possível compreender o presente com base no estudo da origem do direito no passado. Neste sentido, Tylor (apud PINHEIRO E BEKHOR, 1997) acrescenta que não parece existir um pensamento humano tão primitivo a ponto de ter perdido sua influência sobre nosso próprio pensamento, nem tão antigo a ponto de ter interrompido sua ligação com a vida atual.

Também Nascimento (1981), defende que não se pode desvincular o Direito de suas origens quando se pretende compreendê-lo melhor no contexto das sociedades dos dias atuais. Além disso, a evolução do Direito não constitui uma sucessão de criações e aniquilamentos, visto que há no Direito algo de constante e de estável que resiste a todas as mutações e que, aliás, dá nexo à atividade do homem legislador.

O Direito, como um dos elementos que integram a sociedade em sua ação dinâmica, está sujeito a influências que, inexoravelmente, o modificam e até o transfiguram, mas nele também se distinguem os resíduos ou sinais de suas origens. Desta maneira, pode-se reafirmar a utilidade da História do Direito para o estudo da ciência jurídica.

É através da História do Direito que se estabelece os pontos de contato entre as antigas e as modernas instituições jurídicas. Conforme Beviláqua (apud NASCIMENTO, 1981), se o historiador jurídico pode reatar os elos principais da evolução do Direito, acompanhando as pegadas que ela foi gravando por meio da história, dos costumes e das instituições, é porque os estádios sucessivos se prendem uns aos outros, procedem os mais recentes dos mais remotos. É assim, pois, que se cria melhores condições e maiores facilidades para o exame e compreensão dessas mesmas instituições em seu estado atual. 


\section{CONSIDERAÇÕES FINAIS}

O estudo da História do Direito resulta no despertar do interesse histórico, bem como na utilidade jurídica para a compreensão da origem do ordenamento jurídico e sua ligação com os institutos do passado, no qual o Direito atual tem sua origem. Neste sentido, Wolkmer (2003) ainda acrescenta que a História do Direito só alcança significado real enquanto interpretação crítico-dialética da formação e da evolução das fontes, idéias norteadoras, formas técnicas e instituições jurídicas, tendo como objetivo a transformação presente do conteúdo legal instituído e buscando nova compreensão historicista do Direito num sentido social e humanizador.

O Direito contemporâneo é resultado de uma evolução histórica que se iniciou com as primeiras civilizações. Assim, por exemplo, ao examinar o processo histórico evolutivo da cultura jurídica do Brasil, evidencia-se que, desde seus primórdios, a matriz jurídica trazida e imposta às colônias da América Latina, como o Brasil, advém da implementação e adequação das fontes históricas luso-romanísticas, bem como do processo posterior de assimilação e legado institucional regulador colonialista ibérico, para uma estrutura social dependente e periférica.

Destarte, o estudo da disciplina de História do Direito revela-se de grande importância, uma vez que é por intermédio dessa historicidade que são estabelecidos os pontos de contato entre as antigas e as modernas instituições jurídicas. É inviável desvincular o estudo do direito de suas origens, pois a compreensão de uma legislação exige o conhecimento de sua história.

\section{REFERÊNCIAS}

CARDOSO, Ciro Flamarion S. Uma Introdução à História. 6. ed. São Paulo: Brasiliense, 1981.

CURY, Vera Arruda Rozo. Introdução à Formação Jurídica no Brasil. Campinas: Edicamp, 2002.

GAVAZZONI, Aluisio. História do Direito: dos Sumérios até a nossa era. 2. ed. atual. e aum. Rio de Janeiro: Freitas Bastos, 2002.

MALUF, Marina. Ruídos da Memória. São Paulo: Siciliano, 1995.

NASCIMENTO, Walter Vieira do. Lições de História do Direito. 2. ed. São Paulo: Zahar, 1981. 
PINHEIRO, Ralph Lopes. História Resumida do Direito. 9. ed. Rio de Janeiro: Thex, 2000. PINHEIRO, Ralph Lopes; BEKHOR, Helena Goldenzon. 100 Perguntas de História do Direito. Rio de Janeiro: Biblioteca da universidade Estácio de Sá, 1997.

SIDOU, J. M. Othon. Dicionário Jurídico: Academia Brasileira de Letras Jurídicas. 7. ed. Rio de Janeiro: Forense Universitária, 2001.

WOLKMER, Antônio Carlos. História do Direito no Brasil. 3. ed. rev. e atual. Rio de Janeiro: Forense/ 